\title{
Respiratory health and quality of life in young exclusive, habitual smokers - a comparison of waterpipe smokers, cigarette smokers and non-smokers
}

\author{
F I Hawari \\ N A Obeidat ${ }^{2}$ \\ M Abu Alhalawa ${ }^{2}$ \\ Z Al-Busaidi ${ }^{3}$ \\ B Amara ${ }^{4}$ \\ $S$ Baddar $^{3}$ \\ M Elhabiby ${ }^{5}$ \\ H Elkholy ${ }^{5}$ \\ 'Cancer Control Office, King Hussein \\ Cancer Center, School of Medicine, \\ University of Jordan, Amman, Jordan; \\ ${ }^{2}$ Cancer Control Office, King Hussein \\ Cancer Center, Amman, Jordan; \\ ${ }^{3}$ Department of Medicine, Sultan Qaboos \\ University Hospital, Muscat, Oman; \\ ${ }^{4}$ Faculty of Medicine, Sidi Mohamed Ben \\ Abdellah University, Fez, Morocco; \\ ${ }^{5}$ Department of Neurology and \\ Psychiatry, Faculty of Medicine, Ain \\ Shams University, Cairo, Egypt
}

This article was published in the following Dove Press journal:

International Journal of Chronic Obstructive Pulmonary Disease

Purpose: Waterpipe (WP) use has become a global trend in young populations. However, there are few well-controlled studies focusing specifically on the chronic effects of exclusive WP use on young adults' respiratory health. We sought to compare in young adults the burden of respiratory symptoms in regular WP smokers (WPS) relative to regular cigarette smokers (CS, positive controls) and non-smokers (negative controls); and to evaluate differences in health-related quality of life between the three groups.

Method: We implemented a cross-sectional survey in college campuses across four countries (Egypt, Jordan, Morocco and Oman). Purposive sampling was employed to identify habitual (regular) healthy WPS (smoked 3 or more WP per week for 3 or more years); CS (smoked 5 or more cigarettes daily for 3 or more years); and non-smokers. Respiratory symptoms were assessed using the European Community Respiratory Health Survey and the American Thoracic Society and the Division of Lung Diseases Questionnaire. Health-related quality of life was measured using the Short-Form 12. Demographic, environmental and lifestyle factors also were measured.

Result: The analytic sample included 135 WPS, 303 CS, and 300 non-smokers. Either tobacco group had significantly greater proportions of males than the non-smoker group. A significantly lower proportion of non-smokers (than either tobacco group) was overweight or obese. Average numbers of reported respiratory symptoms were 5.1, 5.8, and 2.9 in WPS, $\mathrm{CS}$, and non-smokers, respectively. In multivariable regressions controlling for environmental exposures, body mass index, and physical activity, WPS and CS exhibited significantly higher rates of respiratory symptoms than non-smokers (1.6 times greater and 1.9 times greater rate of respiratory symptoms than non-smokers, respectively). Non-smokers reported significantly higher scores for general health relative to either WPS or CS.

Conclusion: Relative to their young non-smoking counterparts, young habitual WPS exhibit a significant burden of respiratory symptoms that is comparable to that observed with CS. Young WPS (and CS), despite their age, may be well on their way to developing respiratory disease.

Keywords: tobacco, hookah, cough, phlegm, lung diseases, early onset

\section{Introduction}

It is well-established that tobacco use is the leading cause of the global Chronic Obstructive Pulmonary Disease (COPD) burden, ${ }^{1}$ and that smoking needs to be urgently addressed well in advance of a COPD diagnosis. ${ }^{2}$ In the Eastern Mediterranean region, where the prevalence of smoking is particularly high, ${ }^{3}$ there
Correspondence: F I Hawari

Section of Pulmonary and Critical Care Cancer Control Office, King Hussein Street, P.O. Box 1269 Al-Jubeiha, Amman II94I, Jordan

Tel +96265300460 ext 5240

Fax +962 65342567

Email fhawari@khcc.jo
International Journal of Chronic Obstructive Pulmonary Disease 2019:14 18/3-1824

1813

DovePress $f$ in $\boldsymbol{v}$ 
has been a dramatic increase in the reported numbers of COPD cases. ${ }^{4}$ The region also has witnessed a rise in waterpipe (WP) smoking, and the latter is now the most common form of tobacco used among youth in the region. ${ }^{5}$ This epidemic warrants concern given the toxicant profile of WP smoke, ${ }^{6,7}$ and its association with respiratory diseases such as chronic bronchitis, COPD, and lung cancer. ${ }^{8-10}$

Respiratory symptoms are now acknowledged to be sensitive indicators of smoking-induced airway disease. ${ }^{2,11,12}$ In young adulthood in particular, respiratory symptoms are important because wide variations in lung volume can deter airway disease diagnosis using conventional spirometry. ${ }^{12}$ In fact, subjects with respiratory symptoms have been compared to those with mild-to-moderate airflow obstruction and COPD in terms of medical management. ${ }^{2}$ In animal studies, chronic exposure to WP has been shown to cause alveolar damage and airspace expansion, and to prompt an inflammatory airway response. ${ }^{13-15}$ Consistent with these preclinical studies, studies evaluating the respiratory health effects of WP specifically in young users have associated WP smoking with early onset of damage and with the occurrence of respiratory symptoms. ${ }^{16-19}$ However, these studies, while useful and indicate detrimental chronic respiratory and health effects of WP use, were limited in size and varied in their definitions of WP exposure. For example, Hawari et al compared respiratory symptoms (phlegm, shortness of breath, cough, chest illnesses, coughing and phlegm episodes, colds, wheezing) as well as various cardiopulmonary measures in 69 habitual (regular), exclusive young male WP users relative to 69 non-smokers; ${ }^{16}$ Walters et al compared epigenetic changes (DNA methylation of the small airway epithelium) in 7 light, exclusive WP smokers to 7 nonsmokers; ${ }^{17}$ Husain et al studied peak expiratory flow rates, asthma, frequency of respiratory infections, persistent cough, shortness of breath, and chest pain in 525 male students; and although roughly $46 \%$ were smokers, only 52 of the 525 were exclusive WP smokers and reported variable smoking habits (from less than once a week to daily); ${ }^{18}$ finally, StruloviciBarel et al compared 19 non-smokers and 21 light, exclusive WP users to assess cough, sputum production, lung function, and various biological respiratory measures. ${ }^{19}$

Supplementing the above-mentioned studies with wellcontrolled and sufficiently powered research can be of value in confirming the respiratory harms induced by exclusive WP use, specifically among young, exclusive WP smokers with comparable exposure.

This research builds on a previously conducted pilot study about the detrimental respiratory health effects of exclusive habitual WP smoking in young WP users. ${ }^{16}$ We sought to confirm the respiratory outcomes of WP use from our pilot study on a larger scale across four Arab countries (Egypt, Jordan, Morocco and Oman) as well as compare respiratory measures between WP and cigarette smokers, and whether or not differences in health-related quality of life also existed, given the evidence suggesting WP use negatively impacted quality of life in young users. ${ }^{20-22}$ We included both cigarette smokers and non-smokers as positive and negative controls to benchmark our WP results. We hypothesized that young, habitual WP-only smokers would report more respiratory symptoms and poorer overall quality of life than never-smokers; and that WP smokers would be comparable to cigarette-only smokers in respiratory and quality of life measures.

There is a misperception among WP users that it is a safer tobacco product [than the cigarette]. ${ }^{23}$ Smokers, particularly if young, may feel far-removed from severe diseases. ${ }^{24-26}$ Thus, demonstrating through a larger study the respiratory harms of WP use in young adults can enable tobacco control experts to present more compelling evidence about the harms of WP in a context that is directly relevant to this age demographic, particularly when tied to the prognostic value of respiratory symptoms. Otherwise, young adults remain liable to believing that WP is safe to use while young, or is only harmful in a context (in terms of time, age group and disease) that does not apply to them.

\section{Materials and methods Ethical review}

This study was approved by the Institutional Review Board at King Hussein Cancer Center (Jordan); and by research regulatory bodies at Ain Shams University (Egypt), Sidi Mohamed Ben Abdellah University (Morocco), and Sultan Qaboos University (Oman). All adult participants provided verbal consent to participate in this study because the research presented no more than minimal risk to the participants and did not involve procedures for which written consent is normally required outside of the research context.

\section{Setting and sample}

The study was conducted in four university campuses in Cairo (Egypt), Amman (Jordan), Fez (Morocco), and 
Muscat (Oman) using students as subjects. Purposive sampling was performed in order to recruit students who, similar to our previous research, ${ }^{16,27}$ were aged at least 18 years and not more than 27; did not suffer from any chronic health conditions (ie cardiovascular or lung disease including asthma and allergies; liver disease; kidney disease; and diabetes); and were either non-smokers; regular WP smokers who smoked at least three WP sessions a week for the past three years at least; ${ }^{16}$ or regular cigarette smokers who smoked at least five cigarettes a day for the past three years at least. According to Shafagoj et al., ${ }^{28}$ the nicotine level of someone who smokes one WP/day is comparable to the plasma nicotine level of someone who smokes 10 cigarettes/day. Using these estimates, our WP smokers would be smoking the equivalent of $0.43 \mathrm{WP} /$ day. Based on the rough equivalence of one WP/day to 10 cigarettes/day, $0.43 \mathrm{WP} /$ day was therefore considered equivalent to 4.3 (approximately five) cigarettes/day. This is consistent with the rough (and cautious) equivalence of 10 cigarettes to a 45 min WP session which Jawad et al propose. ${ }^{29}$ We therefore included smokers who smoked at least five cigarettes daily (for the past three years at least).

Dual (both cigarette and WP) users, users of other forms of tobacco, and ex-smokers were excluded from the study.

\section{Study design}

We employed a cross-sectional survey-based study design. Data collection lasted from January 2017 to July 2018. Trained data collectors in each country were responsible for screening and recruiting students, and for administering one part of the questionnaire (the respiratory symptoms section). The remainder of the survey was self-administered.

Sample size: Power and Sample Size Calculations software Version 3.1.2 was used to calculate the required sample size. ${ }^{30}$ The effect size was based on available studies regarding tobacco use and its association with respiratory symptoms and quality of life. ${ }^{16,20}$ Accordingly, we assumed that the proportion of WP users reporting cough or phlegm to be $14-18 \%$ higher than the proportion reporting these in non-smokers; and that the overall quality of life score would be roughly ten points lower in WP smokers than non-smokers. A type I error rate of $5 \%$ and a power of $80 \%$ were used. A case: control ratio of 1:3 was used to improve the overall power of the study. We calculated an overall sample size of 630 subjects: 270 exclusive cigarette smokers, 270 never-smokers and 90 exclusive WP smokers. We also oversampled due to the possibility of incomplete data entry. Finally, to ensure a sufficient number of exclusive habitual WP users could be reached, the overall sample was planned to be across the four countries (45\% from Jordan, 25\% from Egypt, 20\% from Morocco and 10\% from Oman). This distribution was based on the prevalence of WP smoking in each one of the countries, ${ }^{31,32}$ as well as the population density in these countries.

\section{Variables and measurement instrument}

This study assessed the association between smoking status (non-smoker; regular WP smoker; regular cigarette smoker) and two outcomes of interest: general respiratory symptoms and quality of life; while adjusting for other lifestyle factors that may have influenced respiratory health and quality of life. Accordingly, the survey was composed of four sections:

Section measuring tobacco-related practices and knowledge: Cigarette smoking patterns (age of initiation, years of smoking; daily cigarette consumption; and intention to quit) and WP smoking patterns (age of initiation, years of smoking, WP sessions per week, WP heads per session, type of WP typically smoked (flavored or not), whether or not the WP was usually shared; locations where WP smoking usually took place; and intention to quit in the next month, six months, or not at all) were measured. For all students, tobacco-related knowledge of cigarette and WP harm ("do you think WPs are harmful?"; "do you think cigarettes are harmful?"; "do you think WP is more/less/similar in harm when compared to the cigarette"); and exposure to secondhand smoke and censer smoke (daily, few times a week, few times a month, never) were measured.

Respiratory symptoms section: This was largely based on questions related to general respiratory symptoms in the European Community Respiratory Health Survey II (questions 1 through 12, covering wheezing, coughing, shortness of breath, phlegm production, chest illnesses and difficulty breathing). ${ }^{33}$ Two additional questions were included from the American Thoracic Society and the Division of Lung Diseases, ATS-DLD-78 questionnaire: ${ }^{34}$ a question about cough accompanied by phlegm, and a question about colds and chest illness).

Quality of life section: Although the Short Form (SF) 36 was piloted for the study, students' complaints about the length of the survey rendered the SF-12 more practical, and it was therefore used in the final tool to elicit and compare quality of life scores (physical functioning; role-physical; 
bodily pain; general health; vitality; social functioning; roleemotional; and mental health) across groups. ${ }^{35-38}$

Section covering academic and sociodemographic characteristics (gender, age, marital status, college year, academic performance, and pocket money); and lifestyle characteristics such as diet, exercise, body mass index (BMI): Academic performance was measured categorically (Distinction, Excellent, Very good, Good, Acceptable, Fail). Pocket money was measured categorically using cut-offs relevant to each country, and standardized to create three groups: low pocket money group, middle pocket money group, and high pocket money group. Seven items were used to briefly measure diet and physical activity. ${ }^{39,40}$ Specifically, students were asked to report the frequency of strenuous activity they performed (ranging from daily to once a month or less) per week or month, as well as the number of hours (per week) they were engaged in strenuous activity. Students were also asked to report their intake of fruits, vegetables, fish, and sweets (ranging from daily to once a week or less).

\section{Statistical analysis}

Descriptive bivariate analyses were conducted to compare WP smokers, cigarette smokers and non-smokers across respiratory symptoms, quality of life scores, and lifestyle-related practices and academic achievement. Chi square statistics were run to test for bivariate distributional differences in categorical variables across tobacco groups. With regards to differences in normally-distributed continuous variables across tobacco groups, independent $t$-tests (if comparing two groups) and ANOVA (one-way and pairwise) were used to measure bivariate distributional differences. Mann-Whitney and Kruskal-Wallis tests were used if the continuous variable failed the normality assumption. Šidák-Holm adjusted $p$ values also were generated. ${ }^{41,42}$

Multivariable regressions were run to compare the rates of respiratory symptoms between WP smokers and non-smokers and cigarette smokers and non-smokers. We adjusted for factors that were relevant to respiratory health in general (and were significantly associated with tobacco use at a bivariate level). Specifically, a negative binomial regression model was used to model the count of respiratory symptoms across groups (controlling for second hand smoking exposure, censer smoke exposure, living near a factory, being overweight or obese, and leading an active lifestyle). Finally, logistic regressions were used to estimate the likelihood of specific respiratory symptoms (such as cough or phlegm) occurring in WP smokers and cigarette smokers (versus non-smokers) after multivariable adjustment.

\section{Results \\ Descriptive results}

The final sample was composed of 135 WP smokers, 303 cigarette smokers, and 300 non-smokers. Either tobacco group was composed of significantly greater proportions of males than the non-smoker group.

Tobacco use patterns for WP and cigarette smokers are displayed in Table 1 . Roughly $72 \%$ of WP smokers in the sample smoked between three and six sessions weekly, while approximately $71 \%$ of cigarette smokers smoked five to 20 cigarettes daily. A significantly greater proportion of cigarette smokers than WP smokers reported past quit attempts, with cigarette smokers reporting a greater average number of past quit attempts. More cigarette smokers than WP smokers also were planning to quit smoking in the next one to six months.

With regards to tobacco-related variables, non-smokers were significantly less likely to be exposed to secondhand smoke than either group of smokers. Although the majority $(>80 \%)$ of the sample agreed that both WP and cigarettes were harmful, differences were observed with regards to perceived relative harm of the WP when compared to the cigarette. For example, significantly more WP smokers (than cigarette smokers or non-smokers) believed the WP was less harmful than the cigarette $(35.6 \%$ of WP smokers, versus $13.2 \%$ and $8.3 \%$ of cigarette smokers and non-smokers, respectively).

With regards to academic and lifestyle-related characteristics of the sample (Table 2), non-smokers had a significantly lower BMI than either group of smokers. Non-smokers also were less likely to engage in regular intake of sugar (than either group of smokers). Non-smokers were significantly less likely to fall in the highest category of monthly pocket money spent. Finally, a significantly higher proportion of non-smokers (than WP and cigarette smokers) reported an academic ranking of "very good" or higher $(48.0 \%$ of non-smokers versus $32.6 \%$ in WP smokers and $30.0 \%$ in cigarette smokers).

\section{Respiratory symptoms}

The average number of respiratory symptoms experienced was 5.1 (standard deviation 3.5), 5.8 (standard deviation 3.5), and 2.9 (standard deviation 2.8), in WP smokers, cigarette smokers, and non-smokers, respectively. The two groups of smokers reported a comparable number of respiratory symptoms, and both values were significantly higher than that reported for non-smokers. Figure 1 provides a display of the proportions of subjects reporting each respiratory 
Table I Descriptive tobacco-related measures among waterpipe (WP), cigarette and non-smokers

\begin{tabular}{|c|c|c|c|c|}
\hline & $\begin{array}{l}\text { WP smokers } \\
(N=135)\end{array}$ & $\begin{array}{l}\text { Cigarette smo- } \\
\text { kers }(\mathrm{N}=303)\end{array}$ & $\begin{array}{l}\text { Non-smokers } \\
(\mathrm{N}=300)\end{array}$ & $\begin{array}{l}\text { Between-group } \\
\text { comparisons* }\end{array}$ \\
\hline Mean age in years (median, standard deviation) & $21.5(21.4,1.8)$ & $21.7(21.5,1.99)$ & $21.6(21.6,1.99)$ & $\begin{array}{l}\text { No significant overall } \\
\text { difference }(p=0.77)\end{array}$ \\
\hline Gender, \% male & $70.9 \%$ & $95.0 \%$ & $50.3 \%$ & $\begin{array}{l}\text { WP vs NS }(p=0.000) \\
\text { WP vs CS }(p=0.000) \\
C S \text { vs NS }(p=0.000)\end{array}$ \\
\hline $\begin{array}{l}\text { Age of initiation of tobacco use in years, } \\
\text { (median, standard deviation) }\end{array}$ & $16.3(16.5,2.4)$ & $15.7(16.0,2.8)$ & - & $\begin{array}{l}\text { No significant overall } \\
\text { difference }(p=0.058)\end{array}$ \\
\hline $\begin{array}{l}\text { Weekly sessions of WP } \\
3-4 \\
5-6 \\
7-8 \\
9-10 \\
>10\end{array}$ & $\begin{array}{l}47.4 \% \\
24.8 \% \\
13.5 \% \\
6.8 \% \\
7.5 \%\end{array}$ & $\begin{array}{l}- \\
- \\
- \\
- \\
-\end{array}$ & $\begin{array}{l}- \\
- \\
- \\
- \\
-\end{array}$ & - \\
\hline $\begin{array}{l}\text { WP session length } \\
<30 \mathrm{~min} \\
30-60 \mathrm{~min} \\
61-90 \mathrm{~min} \\
91-120 \mathrm{~min} \\
>120 \mathrm{~min}\end{array}$ & $\begin{array}{l}12.6 \% \\
53.3 \% \\
19.3 \% \\
6.7 \% \\
8.2 \%\end{array}$ & $\begin{array}{l}- \\
- \\
- \\
- \\
-\end{array}$ & $\begin{array}{l}- \\
- \\
- \\
- \\
-\end{array}$ & - \\
\hline $\begin{array}{l}\text { WP heads per session } \\
<1 \\
1-2 \\
3-4 \\
>4\end{array}$ & $\begin{array}{l}19.6 \% \\
61.7 \% \\
15.0 \% \\
3.8 \%\end{array}$ & $\begin{array}{l}- \\
- \\
- \\
-\end{array}$ & $\begin{array}{l}- \\
- \\
- \\
-\end{array}$ & - \\
\hline Proportion usually share WP & $67.6 \%$ & - & - & \\
\hline $\begin{array}{l}\text { Daily cigarettes } \\
\qquad \begin{array}{l}\leq 10 \\
11-20 \\
21-30 \\
31-40 \\
>40\end{array}\end{array}$ & $\begin{array}{l}- \\
- \\
- \\
- \\
-\end{array}$ & $\begin{array}{l}27.7 \% \\
43.2 \% \\
17.2 \% \\
6.3 \% \\
5.6 \%\end{array}$ & $\begin{array}{l}- \\
- \\
- \\
- \\
-\end{array}$ & - \\
\hline Ever attempted to quit & $50.4 \%$ & $72.5 \%$ & - & $p=0.000$ \\
\hline $\begin{array}{l}\text { Average number quit attempts (median, } \\
\text { standard deviation) }\end{array}$ & $0.41(0,0.96)$ & $1.6(0.2,0.98)$ & - & $p=0.001$ \\
\hline Intention to quit within I-6 months & $25.2 \%$ & $44.6 \%$ & - & $p=0.001$ \\
\hline Daily secondhand smoke exposure & $65.2 \%$ & $61.4 \%$ & $38.7 \%$ & $\begin{array}{l}\text { WP vs NS }(p=0.000) \\
C S \text { vs NS }(p=0.000) \\
\text { WP vs CS }(p=0.450)\end{array}$ \\
\hline Daily censer smoke exposure & $12.6 \%$ & $9.6 \%$ & $11.0 \%$ & \\
\hline Cigarettes perceived harmful (yes) & $93.3 \%$ & $86.1 \%$ & $93.3 \%$ & $\begin{array}{l}\text { WP vs CS }(p=0.03) \text { CS vs } \\
\text { NS }(p=0.004)\end{array}$ \\
\hline
\end{tabular}

(Continued) 
Table I (Continued).

\begin{tabular}{|c|c|c|c|c|}
\hline & $\begin{array}{l}\text { WP smokers } \\
(\mathrm{N}=\mid 35)\end{array}$ & $\begin{array}{l}\text { Cigarette smo- } \\
\text { kers }(\mathrm{N}=303)\end{array}$ & $\begin{array}{l}\text { Non-smokers } \\
(\mathrm{N}=300)\end{array}$ & $\begin{array}{l}\text { Between-group } \\
\text { comparisons* }\end{array}$ \\
\hline WP perceived harmful (yes) & $81.5 \%$ & $83.2 \%$ & $96.0 \%$ & $\begin{array}{l}\text { WP vs NS }(p=0.000) \\
C S \text { vs NS }(p=0.000) \\
\text { WP vs CS }(p=0.670)\end{array}$ \\
\hline $\begin{array}{l}\text { WP perceived relative harm: less harmful than } \\
\text { cigarettes }\end{array}$ & $35.6 \%$ & $13.2 \%$ & $8.3 \%$ & $\begin{array}{l}\text { WP vs NS }(p=0.000) \\
C S \text { vs NS }(p=0.054) \text { WP vs } \\
C S(p=0.000)\end{array}$ \\
\hline $\begin{array}{l}\text { WP perceived relative harm: more harmful } \\
\text { than cigarettes }\end{array}$ & $37.0 \%$ & $53.8 \%$ & $65.7 \%$ & $\begin{array}{l}\text { WP vs NS }(p=0.000) \\
\text { CS vs NS }(p=0.003) \text { WP vs } \\
\text { CS }(p=0.001)\end{array}$ \\
\hline \multicolumn{5}{|l|}{ Country } \\
\hline Jordan & $46 \%$ & $45 \%$ & $46 \%$ & No significant overall dif- \\
\hline Egypt & $25 \%$ & $27 \%$ & $22 \%$ & ference $(p=0.80)$ \\
\hline Morocco & $17 \%$ & $17 \%$ & $18 \%$ & \\
\hline Oman & $12 \%$ & $11 \%$ & $13 \%$ & \\
\hline
\end{tabular}

Note: *Significance cut-off for Šidák-Holm adjusted $p$-value $<0.004$.

Table 2 Descriptive lifestyle and academic characteristics of the sample (column percentages reported)

\begin{tabular}{|c|c|c|c|c|}
\hline & $\begin{array}{l}\text { Waterpipe smo- } \\
\text { kers }(N=\mid 35)\end{array}$ & $\begin{array}{l}\text { Cigarette smo- } \\
\text { kers }(\mathrm{N}=303)\end{array}$ & $\begin{array}{l}\text { Non-smokers } \\
(\mathrm{N}=300)\end{array}$ & $\begin{array}{l}\text { Between-group } \\
\text { comparisons* }\end{array}$ \\
\hline $\begin{array}{l}\text { Body mass index: mean (median, stan- } \\
\text { dard deviation) }\end{array}$ & $24.3(23.7,3.9)$ & $24.2(23.6,4.1)$ & $22.9(22.4,3.5)$ & $\begin{array}{l}\text { WP vs NS }(p=0.0003) C S \text { vs NS } \\
(p=0.0001)\end{array}$ \\
\hline Eating vegetables atleast once a day & $52.6 \%$ & $47.5 \%$ & $50.3 \%$ & $\begin{array}{l}\text { No significant overall difference } \\
(p=0.59)\end{array}$ \\
\hline Eating fruits atleast once a day & $58.5 \%$ & $48.5 \%$ & $47.0 \%$ & $\begin{array}{l}\text { No significant overall difference } \\
(p=0.07)\end{array}$ \\
\hline Eating fish atleast twice a week & $20.7 \%$ & $22.8 \%$ & $19.0 \%$ & $\begin{array}{l}\text { No significant overall difference } \\
(p=0.52)\end{array}$ \\
\hline Eating sugary snacks, sodas or chips daily & $68.2 \%$ & $61.7 \%$ & $49.3 \%$ & $\begin{array}{l}\text { WP vs NS }(p=0.000) \\
C S \text { vs NS }(p=0.002)\end{array}$ \\
\hline Eating breakfast daily or almost daily & $54.8 \%$ & $55.8 \%$ & $64.3 \%$ & $\begin{array}{l}\text { No significant overall difference } \\
(p=0.055)\end{array}$ \\
\hline Regular exercising" & $25.9 \%$ & $36.0 \%$ & $30.0 \%$ & $\begin{array}{l}\text { No significant overall difference } \\
(p=0.13)\end{array}$ \\
\hline Academic rank "very good" or higher & $32.6 \%$ & $30.0 \%$ & $48.0 \%$ & $\begin{array}{l}\text { WP vs NS }(p=0.003) \\
C S \text { vs NS }(p=0.000)\end{array}$ \\
\hline High pocket money group & $47.4 \%$ & $46.5 \%$ & $32.7 \%$ & $\begin{array}{l}\text { WP vs NS }(p=0.003) \\
C S \text { vs NS }(p=0.000)\end{array}$ \\
\hline
\end{tabular}

Notes: "Defined as performing strenuous exercise atleast 2 to 3 times weekly, for a weekly total of atleast 2 to $3 \mathrm{hrs}$. *Significance cut-off for Šidák-Holm adjusted $p$-value $<0.004$. 
$80.0 \%$

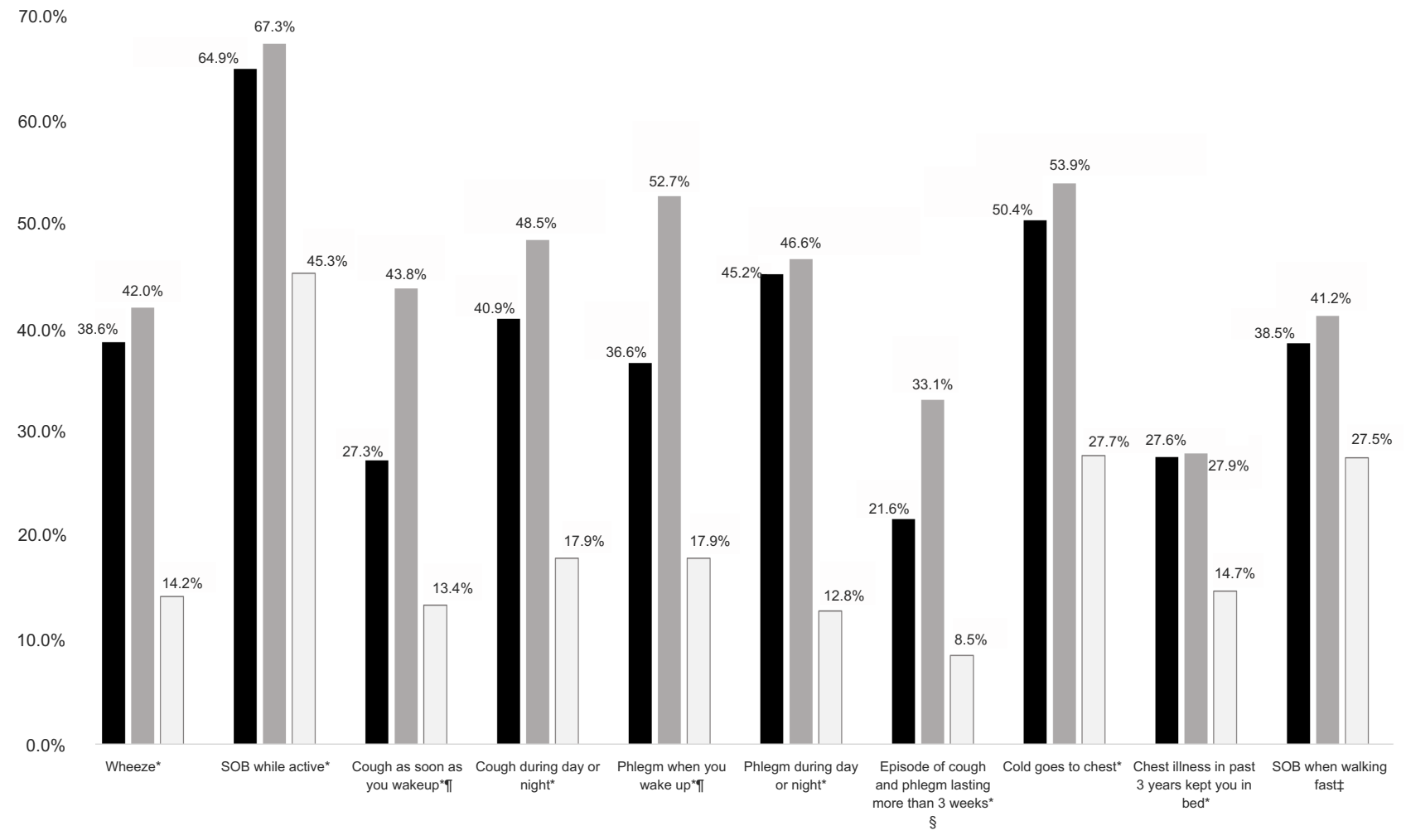

Figure I Proportions reporting each respiratory symptom across waterpipe smokers (WP), cigarette smokers (CS), and non-smokers (NS).

Notes: Please see separate image. *p-value for chi-square statistic comparing waterpipe smokers to non-smokers or cigarette smokers to non-smokers $<0.015$ (significance cut-off for Šidák-Holm adjusted $p$-value). " $p$-value for chi-square statistic comparing waterpipe smokers to cigarette smokers $<0.015$. ${ }^{\S} \mathrm{p}$-value for chi-square statistic comparing waterpipe smokers to cigarette smokers $<0.05$ but $>0.015$. ${ }^{\ddagger} \mathrm{p}$-value for chi-square statistic comparing cigarette smokers to non-smokers $<0.016$; $\mathrm{p}$-value for chisquare statistic comparing waterpipe smokers to non-smokers $<0.05$ but $>0.016$.

symptom across WP smokers, cigarette smokers and nonsmokers. Non-smokers were significantly less likely to report any of the measured respiratory symptoms. When bivariate comparisons were limited to WP and cigarette smokers, a significantly higher proportion of cigarette smokers than WP smokers reported cough upon waking and phlegm upon waking. WP and cigarette smokers were otherwise comparable across other respiratory symptoms.

In multivariable regression analysis of number of respiratory symptoms reported by each group, controlling for other variables that may have impacted respiratory health, both WP and cigarette smokers continued to exhibit a significantly higher number of respiratory symptoms than non-smokers (Table 3). Specifically, after multivariable adjustment (for exposure to secondhand smoke, exposure to censer smoke, living near a factory, being overweight or obese, and engaging in regular physical activity), WP smokers compared to non-smokers had a 1.6 times greater rate of respiratory symptoms (95\% confidence interval 1.4-1.9); while cigarette smokers compared to non-smokers had a 1.9 times greater rate of respiratory symptoms (95\% confidence interval 1.7-2.2). Although the rate of respiratory symptoms was lower among WP smokers than cigarette smokers, it was not statistically different between the two tobacco groups.

Additional multivariate logistic regressions were run to measure the likelihood of reporting cough and phlegm, two respiratory-specific symptoms of importance, ${ }^{2,11}$ across the three groups. The likelihood of reporting cough and phlegm ("usually present during night or day") were significantly higher in both WP and cigarette smokers (than in non-smokers), but comparable statistically between the two groups of smokers. However, cigarette smokers were significantly more likely (than either non-smokers or WP smokers) to report cough or phlegm upon waking, and to report an episode of cough with phlegm that lasted at least 3 weeks. 
Table 3 Multivariable negative binomial regression model of count of respiratory symptoms in waterpipe smokers (WP), cigarette smokers (CS) compared to non-smokers (incidence rate ratios presented)

\begin{tabular}{|l|l|}
\hline & $\begin{array}{l}\text { Incidence rate ratio } \\
\text { (95\% confidence interval) }\end{array}$ \\
\hline $\begin{array}{l}\text { Smoking status } \\
\text { Non-smoker } \\
\text { Waterpipe smokers* } \\
\text { Cigarette smokers }\end{array}$ & $\begin{array}{l}\text { Reference group (I.0) } \\
\text { I.6 (I.4-I.9) } \\
1.9(1.7-2.2)\end{array}$ \\
\hline $\begin{array}{l}\text { Daily second hand smoking } \\
\text { exposure (versus less than daily)* }\end{array}$ & $1.2(1.1-1.4)$ \\
\hline $\begin{array}{l}\text { Daily censer smoke exposure } \\
\text { (versus less than daily) }\end{array}$ & $1 . I(0.95-1.4)$ \\
\hline $\begin{array}{l}\text { Living near a factory (versus not } \\
\text { living near one)* }\end{array}$ & $1.3(1.1-1.6)$ \\
\hline $\begin{array}{l}\text { Being overweight or obese } \\
\text { (versus having a BMI <25) }\end{array}$ & $1 . I(0.93-1.2)$ \\
\hline $\begin{array}{l}\text { Active lifestyle (versus not per- } \\
\text { forming regular exercise) }\end{array}$ & $0.88(0.78-0.99)$ \\
\hline
\end{tabular}

Note: *Incidence rate ratio ( $95 \%$ confidence interval) for waterpipe smokers when using positive controls (cigarette smokers) as the reference group: 0.87 (0.75-I.0).

\section{Quality of life}

Non-smokers reported significantly higher scores for general health relative to either WP or cigarette smokers, and significantly higher physical health scores relative to only cigarette smokers. Cigarette smokers also displayed the worst scores for the physical limitations domain (significantly lower than either WP smokers or non-smokers). Conversely, non-smokers reported the lowest score on the emotional limitations domain, which reached significance only when comparing WP smokers to non-smokers (Table 4). No other significant differences were observed among other quality of life domains.

\section{Discussion}

Our study aimed to determine the early respiratory health effects of habitual WP smoking lasting at least three years, using both non-smokers and cigarette smokers as reference groups. The study is unique in that - by virtue of its regional scope - it was adequately sized for statistical comparisons, and addressed both respiratory and quality of life outcomes while adjusting for other lifestyle-related confounders. Using measures that have been found to be

Table 4 Quality of life mean scores reported by waterpipe smokers (WP), cigarette smokers (CS) and non-smokers (NS)

\begin{tabular}{|c|c|c|c|c|}
\hline & $\begin{array}{l}\text { Waterpipe smokers } \\
(\mathrm{N}=135)\end{array}$ & $\begin{array}{l}\text { Cigarette smokers } \\
(\mathrm{N}=303)\end{array}$ & $\begin{array}{l}\text { Non-smokers } \\
(\mathrm{N}=300)\end{array}$ & Pairwise comparisons* ף \\
\hline $\begin{array}{l}\text { General health: mean } \\
\text { (median, standard deviation) }\end{array}$ & $61.8(62.5,25.4)$ & $57.0(50.0,28.3)$ & $68.1(75.0,25.1)$ & $\begin{array}{l}C S \text { vs NS }(p=0.000 I) \\
\text { WP vs NS }(p=0.0127) \\
\text { WP vs CS }(p=0.085)\end{array}$ \\
\hline $\begin{array}{l}\text { Physical health: mean } \\
\text { (median, standard deviation) }\end{array}$ & $65.6(75.0,32.9)$ & $61.6(75.0,32.1)$ & $69.9(75.0,31.9)$ & $\begin{array}{l}\text { CS vs NS }(p=0.0007) \\
\text { WP vs NS }(p=0.180)\end{array}$ \\
\hline $\begin{array}{l}\text { Social health: mean } \\
\text { (median, standard deviation) }\end{array}$ & $69.7(75.0,30.9)$ & $67.6(75.0,29.9)$ & $69.6(75.0,29.0)$ & $\begin{array}{l}\text { No significant overall difference } \\
(p=0.6 \mathrm{I} 0)\end{array}$ \\
\hline $\begin{array}{l}\text { Mental health: mean } \\
\text { (median, standard deviation) }\end{array}$ & $62.1(60.0,19.6)$ & $58.0(60.0,21.7)$ & $59.9(60.0,20.7)$ & $\begin{array}{l}\text { No significant overall difference } \\
(p=0.290)\end{array}$ \\
\hline $\begin{array}{l}\text { Emotional limitations: mean } \\
\text { (median, standard deviation) }\end{array}$ & $60.9(100,44.1)$ & $54.1(50.0,43.1)$ & $48.4(50.0,45.1)$ & $\begin{array}{l}\text { WP vs NS }(p=0.007) \\
\text { WP vs CS }(p=0.140) \\
C S \text { vs NS }(p=0.123)\end{array}$ \\
\hline $\begin{array}{l}\text { Physical limitations: mean } \\
\text { (median, standard deviation) }\end{array}$ & $69.0(100,41.5)$ & $59.5(50.0,42.6)$ & $68.0(100,42.3)$ & $\begin{array}{l}C S \text { vs WP }(p=0.023) \\
C S \text { vs NS }(p=0.008)\end{array}$ \\
\hline $\begin{array}{l}\text { Vitality: mean (median, standard } \\
\text { deviation) }\end{array}$ & $56.6(60.0,26.4)$ & $56.6(60.0,27.0)$ & $56.4(60.0,24.6)$ & $\begin{array}{l}\text { No significant overall difference } \\
(p=0.993)\end{array}$ \\
\hline $\begin{array}{l}\text { Pain: mean (median, standard } \\
\text { deviation) }\end{array}$ & $79.7(75.0,21.8)$ & $77.9(75.0,22.4)$ & $79.2(75.0,23.2)$ & $\begin{array}{l}\text { No significant overall difference } \\
(p=0.570)\end{array}$ \\
\hline
\end{tabular}

Notes: *Pairwise ANOVA (if normally distributed) or medians/rank-sum (if failing the normality assumption). "Significance cut-off for Šidák-Holm adjusted $p$-value $<0.008$. 
important signals of potential pulmonary disease (respiratory symptoms), ${ }^{2,11,12,43}$ we found that WP smoking was comparable in its direction and overall extent of damage to cigarette smoking. This finding is consistent with what we know of the respiratory toxicity profile of both cigarettes and WP; ${ }^{6,10}$ and can be used to directly address the fallacies among youth and young adults that WP smoking is relatively harmless to them, and that respiratory damage at a young age is unlikely. ${ }^{25,44-48}$

Our interest in respiratory symptoms as a measurable outcome is important to emphasize. Increasingly, there has been a shift in focus from spirometric measures that have conventionally been used to detect the onset of respiratory disease. This is because studies are demonstrating, through clinical [respiratory] symptoms, that disease may be underway even before significant changes in spirometry are detected. And while these studies have been conducted in relatively older cigarette-smoking adults who are being managed as COPD patients, ${ }^{12,49}$ the prevalence estimates for specific respiratory symptoms in our young sample are not far in value from those reported in these studies. This in turn highlights the dire health situation at hand with young habitual WP and cigarette smokers.

Our data demonstrated that, with regards to respiratory health, both types of smoking induced significantly alarming symptoms in comparison to non-smokers. The overall number of respiratory symptoms reported by both groups of smokers was significantly higher than in non-smokers (and not significantly different between the two groups of smokers). Comparable proportions of both groups of smokers reported specific respiratory symptoms (wheezing, shortness of breath, cough or phlegm usually present at any time, a cold that goes to the chest, and a chest illness that kept one in bed); and both proportions (reported in WP and cigarette smokers) were significantly higher than those in non-smokers. Not surprisingly, both groups of smokers also reported significantly lower general health scores than non-smokers.

There were a few respiratory symptoms that were observed to be significantly more frequent in cigarette smokers than WP smokers (and cigarette smokers fared worse in physical quality of life aspects). Such differences may be due to more than one reason. Cigarette smokers in our sample initiated smoking at a younger age (borderline significance), and a substantial proportion of them (40\%) smoked a pack or more daily. Furthermore, roughly $28 \%$ of WP smokers smoked seven or more times a week, indicating the latter were not exposed on a daily basis to tobacco smoke in the same way cigarette smokers were. In addition, about $67 \%$ of WP smokers tended to share their WP, which is likely to attenuate exposure. There also are inherent differences between cigarettes and WPs (for example they differ in accessibility and ease of assembly, rendering the cigarette more likely to be used more frequently on a daily basis). Finally, while both cigarette and WP smoke contain toxic chemicals, the exact mix and concentration of these chemicals differs between the two. ${ }^{6,7}$ It is therefore not unusual that, while both WP smoking and cigarette smoking induce serious respiratory damage, the trajectory of harm may differ between them.

There were other findings in our study that warrant concern with regards to WP use. Although WP and cigarette smokers exhibited comparable harms, WP users were less likely to attempt to quit, and substantially less WP users expressed intention to quit within the next month or the next six months. There also were differences in the brief measures of perceived harm that we used. No more than roughly a quarter of the entire sample believed WP and cigarette smoking were similarly harmful (while more cigarette and non-smokers than WP smokers believed WP to be more harmful). Furthermore, although the association between smoking and weight gain is a multifactorial and variable one which takes decades to unfold, ${ }^{50}$ it is noteworthy that, similar to other findings, ${ }^{51}$ our sample of WP smokers, even at a younger age, had a significantly higher BMI than non-smokers. Cigarette smokers also had a significantly higher BMI than non-smokers. It is unclear if tobacco use may be associated with a lifestyle that leads to a higher BMI (tobacco users in our sample were more likely to consume sugary foods on a daily basis), or if those who perceive themselves to be overweight resort to tobacco use to try to lose weight. Nevertheless, our findings are relevant because they indicate that, in addition to respiratory harms, WP use in young adults is associated with other unhealthy lifestyle factors.

With regards to quality of life, differences in prevalence of respiratory symptoms translated only to differences in overall quality of life scores. With regards to mental health, WP smokers reported the highest scores with regards to "emotional limitations", followed by cigarette smokers. This is inconsistent with what other studies have found. ${ }^{20-22} \mathrm{We}$ speculate that our sample of tobacco users may rely heavily on smoking as a form of coping, and that tobacco use is associated with a more social lifestyle that may facilitate emotional functionality in Middle Eastern young adults. Youth have reported WP use as an alternative recreational 
activity, or as a means to relax, to address loneliness and boredom, to socialize, or to experience a positive somatic effect. $^{52}$ It is therefore possible that achieving this produces the higher scores for emotional well-being we observe in our sample of young Middle Eastern users.

Our study has some limitations. We employed purposive rather than random sampling, due to logistic constraints. Nevertheless, we ensured that data collectors frequented gathering sites across university campuses (rather than focus on only a few locations). We also did not track the number of screened subjects who refused or were ineligible to participate. In addition, the cross-sectional nature of our study design made it difficult to ascertain the temporal nature of damage induced by smoking. Finally, although the direction of effects trended similarly within countries, inter-country variability in effect size is possible. However, the study was not powered to detect differences between countries. Rather, it used a regional scope to ensure that a sufficient number of habitual WP users could be recruited.

In summary, our study contributes uniquely to the literature on WP health effects by focusing on respiratory and quality of life measures in a relatively homogenous (in terms of tobacco use) and sufficiently sized sample of young WP users. Despite their age, we found that regular exclusive WP smokers and regular exclusive cigarette smokers reported significantly greater [than non-smokers] respiratory symptoms such as cough and phlegm, early symptoms of respiratory disease.

\section{Conclusion}

Relative to their young non-smoking counterparts, young habitual WP smokers exhibit a significant burden of respiratory symptoms that is comparable to that observed with cigarette smokers. Young WP smokers (and cigarette smokers), despite their age, may be well on their way to developing respiratory disease.

\section{Acknowledgment}

This research was supported by funds from the Intramural Research Grant Program at King Hussein Cancer Center. The authors gratefully acknowledge the data collection efforts of Ahmad Abdallah, Nida AbdelAziz, Firas Al Amri, Ibrahim Al Shezawi, Mohammad AlZoubaidi, Mariam Atassi, Osama Bassah, Issa Deir, Sarah Ibrahiem, Hala Lobani, Raghad Maraghi, Omar Yehia Mansour, Mahmoud Morsy, Asal Nakhleh, Osama Oudat, Rawan Qawasmeh, Diala Zraikat, and Jamil Zraikat. The authors also thank Professor Omar Al-Rawas from the Department of Medicine at Sultan Qaboos University, and Dr. Gihan EINahas from the Department of Neurology and Psychiatry (Faculty of Medicine at Ain Shams University) for their general administrative support.

\section{Disclosure}

The authors report no conflicts of interest in this work.

\section{References}

1. Laniado-Laborin R. Smoking and chronic obstructive pulmonary disease (COPD). Parallel epidemics of the 21 century. Int $J$ Environ Res Public Health. 2009;6(1):209-224. doi:10.3390/ijerph6010209

2. Fabbri LM. Smoking, not COPD, as the disease. $N$ Engl J Med. 2016;374(19):1885-1886. doi:10.1056/NEJMe1515508

3. World Health Organization. Global Health Observatory (GHO) data. Prevalence of tobacco smoking. Available from: http://gamapserver. who.int/gho/interactive_charts/tobacco/use/atlas.html. Accessed July $18,2019$.

4. Adeloye D, Chua S, Lee C, et al. Global and regional estimates of COPD prevalence: systematic review and meta-analysis. J Glob Health. 2015;5(2):020415. doi:10.7189/jogh.05.020415

5. Jawad M, Charide R, Waziry R, Darzi A, Ballout RA, Akl EA. The prevalence and trends of waterpipe tobacco smoking: A systematic review. PLoS One. 2018;13(2):e0192191. doi:10.1371/journal.pone.0192191

6. Primack BA, Carroll MV, Weiss PM, et al. Systematic review and metaanalysis of inhaled toxicants from waterpipe and cigarette smoking. Public Health Rep. 2016;131(1):76-85. doi:10.1177/003335491613100114

7. Shihadeh A, Schubert J, Klaiany J, El Sabban M, Luch A, Saliba NA. Toxicant content, physical properties and biological activity of waterpipe tobacco smoke and its tobacco-free alternatives. Tob Control. 2015;24 Suppl 1:i22-i30. doi:10.1136/tobaccocontrol-2014-051907

8. Haddad L, Kelly DL, Weglicki LS, Barnett TE, Ferrell AV, Ghadban R. A systematic review of effects of waterpipe smoking on cardiovascular and respiratory health outcomes. Tob Use Insights. 2016;9:13-28. doi:10.4137/TUI.S39873

9. Montazeri Z, Nyiraneza C, El-Katerji H, Little J. Waterpipe smoking and cancer: systematic review and meta-analysis. Tob Control. 2017;26(1):92-97. doi:10.1136/tobaccocontrol-2015-052758

10. Waziry R, Jawad M, Ballout RA, Al Akel M, Akl EA. The effects of waterpipe tobacco smoking on health outcomes: an updated systematic review and meta-analysis. Int J Epidemiol. 2017;46(1):32-43. doi:10.1093/ije/dyw021

11. Woodruff PG, Barr RG, Bleecker E, et al. Clinical significance of symptoms in smokers with preserved pulmonary function. $N$ Engl $J$ Med. 2016;374(19):1811-1821. doi:10.1056/NEJMoa1505971

12. Regan EA, Lynch DA, Curran-Everett D, et al. Clinical and radiologic disease in smokers with normal spirometry. JAMA Intern Med. 2015;175(9):1539-1549. doi:10.1001/jamainternmed.2015.2735

13. Khabour OF, Alzoubi KH, Al-Sawalha N, Ahmad MB, Shihadeh A, Eissenberg T. The effect of chronic exposure to waterpipe tobacco smoke on airway inflammation in mice. Life Sci. 2018;200:110-114. doi:10.1016/j.1fs.2018.03.034

14. Alzoubi A, Ghazwi R, Alzoubi K, et al. Vascular endothelial growth factor receptor inhibition enhances chronic obstructive pulmonary disease picture in mice exposed to waterpipe smoke. Folia Morphol. 2018;77(3):447-455. doi:10.5603/FM.a2017.0120

15. Khabour OF, Alzoubi KH, Abu Thiab TM, Al-Husein BA, Eissenberg T, Shihadeh AL. Changes in the expression and protein level of matrix metalloproteinases after exposure to waterpipe tobacco smoke. Inhal Toxicol. 2015;27(13):689-693. doi:10.3109/ 08958378.2015.1085471 
16. Hawari FI, Obeidat NA, Ghonimat IM, Ayub HS, Dawahreh SS. The effect of habitual waterpipe tobacco smoking on pulmonary function and exercise capacity in young healthy males: A pilot study. Respir Med. 2017;122:71-75. doi:10.1016/j.rmed.2016.11.024

17. Walters MS, Salit J, Ju JH, et al. Waterpipe smoking induces epigenetic changes in the small airway epithelium. PLoS One. 2017;12(3): e0171112. doi:10.1371/journal.pone.0171112

18. Husain H, Al-Fadhli F, Al-Olaimi F, et al. Is smoking shisha safer than cigarettes: comparison of health effects of shisha and cigarette smoking among young adults in Kuwait. Med Princ Pract. 2016;25 (2):117-122. doi:10.1159/000442417

19. Strulovici-Barel Y, Shaykhiev R, Salit J, et al. Pulmonary abnormalities in young, light-use waterpipe (hookah) smokers. Am J Respir Crit Care Med. 2016. doi:10.1164/rccm.201512-2470OC

20. Tavafian SS, Aghamolaei T, Zare S. Water pipe smoking and healthrelated quality of life: a population-based study. Arch Iran Med. 2009;12(3):232-237.

21. Grinberg A. Subjective well-being and hookah use among adults in the United States: a nationally-representative sample. Drug Alcohol Depend. 2015;153:242-249. doi:10.1016/j.drugalc dep.2015.05.020

22. Primack BA, Land SR, Fan J, Kim KH, Rosen D. Associations of mental health problems with waterpipe tobacco and cigarette smoking among college students. Subst Use Misuse. 2013;48(3):211-219. doi:10.3109/10826084.2012.750363

23. Ali M, Jawad M. Health effects of waterpipe tobacco use: getting the public health message just right. Tob Use Insights. 2017;10:1179173x17696055. doi:10.1177/1179173X17696055

24. Dillard AJ, McCaul KD, Klein WM. Unrealistic optimism in smokers: implications for smoking myth endorsement and self-protective motivation. J Health Commun. 2006;11 Suppl 1:93-102. doi:10.1080/ 10810730600637343

25. Masiero M, Lucchiari C, Pravettoni G. Personal fable: optimistic bias in cigarette smokers. Int J High Risk Behav Addict. 2015;4(1) e20939. doi:10.5812/ijhrba

26. Weinstein ND, Marcus SE, Moser RP. Smokers' unrealistic optimism about their risk. Tob Control. 2005;14(1):55-59. doi:10.1136/ tc. 2004.008375

27. Hawari FI, Obeidat NA, Ayub H, et al. The acute effects of waterpipe smoking on lung function and exercise capacity in a pilot study of healthy participants. Inhal Toxicol. 2013;25(9):492-497. doi:10.3109/ 08958378.2013 .806613

28. Shafagoj YA, Mohammed FI, Hadidi KA. Hubble-bubble (water pipe) smoking: levels of nicotine and cotinine in plasma, saliva and urine. Int $J$ Clin Pharmacol Ther. 2002;40(6):249-255. doi:10.5414/cpp40249

29. Jawad M, Khaki H, Hamilton F. Shisha guidance for GPs: eliciting the hidden history. Br J Gen Pract. 2012;62(595):66-67. doi:10.3399/ bjgp12X625030

30. Dupont WD, Plummer WD. Power and sample size calculations: a review and computer program. Control Clin Trials. 1990;11:116-128. Available from: http://biostat.mc.vanderbilt.edu/wiki/Main/ PowerSampleSize. Accessed July 18, 2019.

31. Jawad M, Lee JT, Millett C. Waterpipe tobacco smoking prevalence and correlates in 25 eastern mediterranean and eastern european countries: cross-sectional analysis of the global youth tobacco survey. Nicotine Tob Res. 2016;18(4):395-402. doi:10.1093/ntr/ntv101

32. Khattab A, Javaid A, Iraqi G, et al. Smoking habits in the Middle East and North Africa: results of the BREATHE study. Respir Med. 2012;106 Suppl 2:S16-S24. doi:10.1016/S0954-6111(12)70011-2

33. European Community Respiratory Health Survey II Steering Committee. The European Community Respiratory Health Survey II. Eur Respir J. 2002;20:1071-1079. Survey available from: http:// www.ecrhs.org/Quests/ECRHSIImainquestionnaire.pdf. Accessed July $18,2019$.
34. Ferris BG. Epidemiology Standardization Project (American Thoracic Society). Am Rev Respir Dis. 1978;118(6 Pt 2):1-120.

35. Al Sayah F, Ishaque S, Lau D, Johnson JA. Health related quality of life measures in Arabic speaking populations: a systematic review on cross-cultural adaptation and measurement properties. Qual Life Res. 2013;22(1):213-229. doi:10.1007/s11136-012-0129-3

36. Al-Shehri AH, Taha AZ, Bahnassy AA, Salah M. Health-related quality of life in type 2 diabetic patients. Ann Saudi Med. 2008;28 (5):352-360. doi:10.5144/0256-4947.2008.352

37. Obtel M, El Rhazi K, Elhold S, Benjelloune M, Gnatiuc L, Nejjari C. Cross-cultural adaptation of the 12-Item Short-Form survey instrument in a Moroccan representative Survey. South Afr J Epidemiol Infect. 2015;28 (3):166-171. doi:10.1080/10158782.2013.11441540

38. Younsi M, Chakroun M. Measuring health-related quality of life: psychometric evaluation of the Tunisian version of the SF-12 health survey. Qual Life Res. 2014;23(7):2047-2054. doi:10.1007/s11136014-0641-8

39. Rangul V, Holmen TL, Kurtze N, Cuypers K, Midthjell K. Reliability and validity of two frequently used self-administered physical activity questionnaires in adolescents. BMC Med Res Methodol. 2008;8:47. doi:10.1186/1471-2288-8-47

40. Fredriksson E, Brekke HK, Ellegård L. Validation of four questions on food habits from the Swedish board of health and social welfare by 3-day food records in medical and nursing students. Food Nutr Res. 2017;58(1):23438. doi:10.3402/fnr.v58.23438

41. Stata code fragments. Šidák-Holm adjusted p-values. UCLA: Statistical Consulting Group. Available from: https://stats.idre.ucla edu/stata/code/idak-holm-adjusted-p-values/. Accessed July 18, 2019.

42. Chen SY, Feng Z, Yi X. A general introduction to adjustment for multiple comparisons. J Thorac Dis. 2017;9(6):1725-1729. doi:10.21037/jtd.2017.05.34

43. Martinez CH, Murray S, Barr RG, et al. Respiratory symptoms items from the COPD assessment test identify ever-smokers with preserved lung function at higher risk for poor respiratory outcomes. An analysis of the subpopulations and intermediate outcome measures in COPD study cohort. Ann Am Thorac Soc. 2017;14(5):636-642. doi:10.1513/AnnalsATS.201610-815OC

44. Rahman S, Chang L, Hadgu S, Salinas-Miranda AA, Corvin J. Prevalence, knowledge, and practices of hookah smoking among university students, Florida, 2012. Prev Chronic Dis. 2014;11:E214. doi: $10.5888 /$ pcd11.130272

45. Majeed BA, Sterling KL, Weaver SR, Pechacek TF, Eriksen MP. Prevalence and harm perceptions of hookah smoking among U.S. adults, 2014-2015. Addict Behav. 2017;69:78-86. doi:10.1016/j. addbeh.2017.01.032

46. Wackowski OA, Delnevo CD. Young adults' risk perceptions of various tobacco products relative to cigarettes: results from the national young adult health survey. Health Educ Behav. 2016;43 (3):328-336. doi:10.1177/1090198115599988

47. Cooper M, Pacek LR, Guy MC, et al. Hookah use among U.S. youth: a systematic review of the literature from 2009-2017. Nicotine Tob Res. 2018. doi:10.1093/ntr/nty135

48. Mantler T. A systematic review of smoking Youths' perceptions of addiction and health risks associated with smoking: utilizing the framework of the health belief model. Addict Res Theory [Internet]. Informa UK Limited. 2012;21(4):306-317. doi:10.3109/16066359.2012.727505

49. Tan WC, Bourbeau J, Hernandez P, et al. Exacerbation-like respiratory symptoms in individuals without chronic obstructive pulmonary disease: results from a population-based study. Thorax. 2014;69 (8):709-717. doi:10.1136/thoraxjnl-2013-205048

50. Letcher T, Greenhalgh EM, Winstanley MH. 3.29 Smoking and body weight. In: Scollo MM, Winstanley MH, editors. Tobacco in Australia: Facts and Issues. Melbourne: Cancer Council Victoria; 2015. Available from: http://www.tobaccoinaustralia.org.au/3-29smoking-and-body-weight. Accessed July 18, 2019. 
51. Ward KD, Ahn S, Mzayek F, et al. The relationship between waterpipe smoking and body weight: population-based findings from Syria. Nicotine Tob Res. 2015;17(1):34-40. doi:10.1093/ntr/ ntu121
52. Akl EA, Ward KD, Bteddini D, et al. The allure of the waterpipe: a narrative review of factors affecting the epidemic rise in waterpipe smoking among young persons globally. Tob Control. 2015;24 Suppl 1:i13-i21. doi:10.1136/tobaccocontrol-2014-051906

\section{Publish your work in this journal}

The International Journal of COPD is an international, peer-reviewed journal of therapeutics and pharmacology focusing on concise rapid reporting of clinical studies and reviews in COPD. Special focus is given to the pathophysiological processes underlying the disease, intervention programs, patient focused education, and self management protocols. This journal is indexed on PubMed Central, MedLine and CAS. The manuscript management system is completely online and includes a very quick and fair peer-review system, which is all easy to use. Visit http://www.dovepress.com/testimonials.php to read real quotes from published authors. 